\title{
Os Múltiplos Desafios da Gestão de Terceirizados: a experiência dos gestores de contratos
}

\author{
Yana Torres de Magalhães ${ }^{1}$ \\ Antonio Moreira de Carvalho Neto ${ }^{2}$ \\ Pedro Paulo Barros Gonçalves ${ }^{3}$
}

\section{Resumo}

O objetivo deste artigo é analisar, sob a ótica dos gestores de contratos da Vale, as práticas gerenciais adotadas por essa grande empresa para lidar com os quatro principais desafios da gestão de trabalhadores terceirizados: qualificação; qualidade de serviços; padronização dos serviços e o comprometimento dos terceirizados. Apesar desse quadro já durar pelo menos 20 anos, pouco ainda se discute sobre tais práticas gerenciais, e é essa a maior contribuição deste artigo. $\mathrm{O}$ olhar dos gestores sobre as práticas de recursos humanos em relação aos principais desafios impostos pela terceirização é praticamente inexistente na literatura. Foram realizadas 15 entrevistas semiestruturadas com gestores de contratos de terceirização neste estudo de caso de natureza descritiva. Procedeuse a análise documental de normas sobre terceirização na Vale. Foram identificadas práticas de gestão utilizadas para lidar com cada um dos desafios, sendo a gestão de contratos e a oferta de programas de treinamento as mais destacadas. A legislação trabalhista contribui para que os terceirizados continuem segregados, uma vez que as empresas evitam uma relação mais direta temendo estabelecer vínculo empregatício. Apesar dos vários esforços para que se melhore o trabalho terceirizado, ele ainda é estigmatizado, visto e tratado como inferior ao emprego direto, o que causa impactos negativos no comprometimento. Ainda predomina a preocupação com a economia de custos na decisão da empresa por terceirizar. Portanto, há muito a evoluir para que a terceirização se efetive sem proporcionar prejuízos aos envolvidos neste processo.

Palavras-chave: Recursos Humanos. Desafios da Gestão de Terceirizados. Gestores fiscais de contratos.

\footnotetext{
${ }^{1}$ Mestre e doutoranda em Administração pelo Programa de Pós-Graduação em Administração da Pontifícia Universidade Católica de Minas Gerais. Professora da Fundação Comunitária de Ensino Superior de Itabira. Endereço: Programa de Pós-Graduação em Administração da PUC Minas/FDC. Avenida Itaú, n 525, Bairro Dom Cabral, CEP: 30.535-012 - Belo Horizonte - MG - Brasil. E-mail: yanamagalhaes@hotmail.com.

${ }^{2}$ Doutor em Administração. Professor do Programa de Pós-Graduação em Administração da Pontifícia Universidade Católica de Minas Gerais. Coordenador do NERHURT - Núcleo de Estudos em Recursos Humanos e Relações de Trabalho do PPGA da PUC Minas, que tem o suporte da FAPEMIG - Fundação de Amparo à Pesquisa do Estado de Minas Gerais. Coordenador da Divisão GPR - Gestão de Pessoas e Relações de Trabalho - da ANPAD. Endereço: Programa de Pós-Graduação em Administração da PUC Minas/FDC. Avenida Itaú, nº 525, Bairro Dom Cabral, CEP: 30.535-012 -Belo Horizonte-MG -Brasil. E-mail: carvalhoneto@pucminas.br.

${ }^{3}$ Graduado em Relações Internacionais pela Pontifícia Universidade Católica de Minas Gerais. Bolsista de Iniciação Científica da FAPEMIG - Fundação de Amparo à Pesquisa do Estado de Minas Gerais. Endereço: Programa de Pós-Graduação em Administração da PUC Minas/ FDC. Avenida Itaú, n 525, Bairro Dom Cabral, CEP: 30.535-012 - Belo Horizonte - MG - Brasil. E-mail: pedropbg@yahoo.com.br.

Artigo recebido em: 12/12/2008. Aceito em: 13/04/2009. Membro do Corpo Editorial Científico responsável pelo processo editorial: Gilberto de Oliveira Moritz.
} 


\section{Introdução}

Durante mais da metade do Século $\mathrm{XX}$, o processo hegemônico de produção de mercadorias no modo de produção capitalista centrou-se no modelo fordista baseado em grandes estruturas organizacionais verticalizadas. É consenso na literatura que, com o declínio desse modelo, particularmente a partir dos anos de 1980 nos países centrais e dos anos de 1990 em países em desenvolvimento como o Brasil, desencadeou-se um processo de reestruturação produtiva, caracterizado pelas inovações tecnológicas $e$ organizacionais, tais como a horizontalização das empresas e a terceirização (ANTUNES, 1995; ANTUNES, 1999; CARVALHO NETO, 1997; DRUCK, 1999; HECKSCHER; CARRÉ, 2006; KOCHAN, 2006; LOCKE, 1999).

A terceirização se insere nesse esforço de dotar as empresas de flexibilidade e adaptabilidade em face de um mercado em constante mutação, que exige montagens e desmontagens incessantes de seus arranjos organizacionais.

De acordo com a percepção de gestores de nível estratégico, a contratação de terceirizados por empresas brasileiras de grande porte não dá sinais de queda e pode até mesmo aumentar em um futuro próximo. As empresas brasileiras ainda estão despreparadas para gerir múltiplos vínculos contratuais, ou mesmo, para decidir qual área deve ser mantida $e$ qual deve ser terceirizada (FERNANDES; CARVALHO NETO, 2005).

A pesquisa realizada por Fernandes e Carvalho Neto (2005) foi feita com 513 gestores de 179 empresas brasileiras de grande porte e aponta os maiores desafios frente à gestão de terceirizados, que são: a) contar com uma equipe qualificada de terceirizados; b) garantir a melhoria da qualidade de serviços; c) garantir a padronização dos serviços contratados entre empresa central e terceirizados; e d) obter comprometimento dos terceirizados. Essa pesquisa abre espaço para novas investigações acerca da gestão de múltiplos vínculos contratuais. Porém, como essa investigação foi quantitativa, não coube uma análise mais profunda sobre as práticas de gestão.

Visando contribuir para superar essa lacuna, este estudo desenvolveuse colocando a seguinte questão: como uma empresa nacional de grande porte e com larga experiência em terceirização está lidando com os desafios da gestão de trabalhadores terceirizados? Para responder essa questão, a presente investigação partirá dos quatro principais desafios apontados na pesquisa de Fernandes e Carvalho Neto (2005), citados anteriormente. 
A partir dos estudos desenvolvidos sobre a terceirização no caso brasileiro, percebe-se que há pequenos avanços nas práticas de gestão desse público. Este artigo visa contribuir com os ainda raros estudos sobre a gestão dos trabalhadores terceirizados, ao entender que um estudo de caso sobre o tratamento dado à terceirização numa grande empresa que tem um longo histórico de subcontratação como a Vale pode fornecer subsídios consideráveis para que se aprofunde na discussão desse tema. Assim, este artigo foi desenvolvido a partir do seguinte objetivo: analisar, sob a ótica dos gestores de contratos da Vale, as práticas gerenciais adotadas por essa grande empresa para lidar com os quatro principais desafios da gestão de trabalhadores terceirizados: qualificação; qualidade de serviços; padronização dos serviços e comprometimento dos terceirizados.

\section{Mudanças nas Relações de Trabalho e Generalização da Terceirização: múltiplos desafios para a gestão}

Caracterizados pela rigidez, os tradicionais processos de produção fordista apresentaram-se pouco adequados para atender às necessidades de mercados cada vez mais segmentados e dinâmicos (SABEL; ZEITLIN, 1985; UDERMAN, 2007).

Uma das respostas à baixa adequação no nível organizacional foi a reestruturação produtiva, que se refere à incorporação, nas plantas produtivas, de novas tecnologias de base microeletrônica, assim como novas formas de organização e gestão do trabalho. Tal processo, porém, inscreve-se em um quadro de transformações mais profundas, que não envolvem somente o processo de produção de mercadorias, mas todo um arranjo societal. Essas transformações são uma espécie de resposta à crise do modelo fordista, que até então formava a base da expansão econômica registrada nos países capitalistas centrais e entrou em crise a partir dos anos de 1980. Assim, a reestruturação produtiva visa proporcionar maior flexibilidade gerencial às empresas (ARRIGHI, 1996; BORGES; DRUCK, 1993; CORIAT, 1988; KOLKO, 1988; OLSEN; KALLEBERG, 2004).

A racionalização produtiva tem sido feita com o enxugamento drástico das estruturas empresariais fordistas e com a divisão delas em unidades de produção menores e mais independentes (CARVALHO NETO, 2001). Os processos produtivos têm sido redesenhados, e a utilização de novas 
tecnologias facilita o surgimento de novos arranjos estruturais nas organizações, como a terceirização (CLEGG; HARDY; NORD, 1999). A focalização no negócio da empresa, passando a subcontratar os serviços que não são atividade-fim, generalizou-se há pelo menos duas décadas (KOLKO, 1988; OLSEN; KALLEBERG, 2004).

As organizações passaram a abrigar, predominantemente, três tipos de vínculos com seus trabalhadores:

a) o vínculo tradicional, com carteira de trabalho assinada pela empresa, e garantias trabalhistas expressas, no caso brasileiro, na Consolidação da Legislação do Trabalho (CLT);

b) os contratos temporários de trabalho para suprir necessidades extraordinárias, demandas ocasionais ou inesperadas;

c) a terceirização de atividades e/ou tarefas (LOCKE, 1999; PURCELL; PURCELL, 1998).

Nesse cenário marcado pela competição, a terceirização se apresenta como uma ferramenta adequada, pois visa repassar a terceiros, considerados especialistas em determinadas atividades, parte de suas tarefas, reduzindo com isso os custos e aumentando a eficiência (PURCELL; PURCELL, 1998). As empresas menores - no caso as contratadas - fornecem todo tipo de produtos às empresas contratantes, tais como: insumos, embalagens e força de trabalho (DRUCK, 1999).

Ao optar pela terceirização, a organização deixa um campo conhecido $e$ inicia relações pautadas em algum contrato específico, cujas características são diferentes do contrato de emprego. O contrato de terceirização sempre envolverá pessoas jurídicas, tendo, de um lado, a tomadora ou contratante, e, do outro, a executora das atividades ou contratada, que pode ser uma empresa mercantil ou uma cooperativa de trabalho (WILLIAMSON, 1996). Uma questão muito frisada quando se trata da terceirização é o seu caráter não subordinativo. A contratante não pode ter qualquer tipo de ingerência em relação aos recursos humanos da contratada, pois os trabalhadores envolvidos na atividade são diretamente subordinados à empresa contratada, que é a legítima empregadora (SILVEIRA; SARATT; MORAES, 2002).

A terceirização vem se expandindo significativamente com o passar dos anos, até mesmo em países bastante díspares em relação à estrutura do mercado de trabalho. A terceirização teve significativa expansão tanto na 
Noruega, onde o mercado de trabalho sempre foi mais regulado, quanto nos EUA, que sempre foi mais flexível no tocante à legislação do trabalho (OLSEN; KALLEBERG, 2004).

No Brasil, o processo de terceirização se iniciou com a instalação das multinacionais, por meio das técnicas de gestão trazidas principalmente pelas montadoras de veículos. Apesar das montadoras estarem instaladas no Brasil há cerca de 50 anos, o processo de terceirização foi intensificado a partir de meados da década de 1990, com o aparecimento e o desenvolvimento de fornecedores a partir da demanda por parte das montadoras (RYNGELBLUM, 1999).

Posteriormente, a partir de uma política competitiva, da exigência de aprimoramento da qualidade dos produtos e da eficiência nos serviços de baixo custo, o Brasil passou a priorizar a questão da racionalização econômica como via de obter maior competitividade. Dessa maneira, aos poucos a terceirização começou a ser implementada em atividades consideradas periféricas na produção, como a limpeza e a conservação e segurança patrimonial. Mais tarde ela passou a atingir atividades-meio, tais como vigilância, transportes, informática, reprografia, telecomunicações, manutenção de prédios e equipamentos, dentre outras (CARVALHO NETO, 2001).

Os desdobramentos mais recentes da terceirização permitem compreendê-la como uma ferramenta adotada pelas organizações brasileiras, com delegação de grande parte das atividades de apoio e, diferentemente da sua concepção original, até mesmo de importantes etapas do processo produtivo. Um número significativo de empresas brasileiras adota a terceirização de maneira ampla e intensa chegando a terceirizar até $100 \%$ do seu processo produtivo (LEOCÁDIO; DÁVILA; DONALDEL, 2008).

Segundo Druck (1999) e Alves (2000), a terceirização tem sido fundamental para garantir bons níveis de produtividade e lucratividade, pois:

a) consegue otimizar as escalas produtivas;

b) reduz significativamente os custos administrativos e os custos com a força de trabalho;

c) abre maiores possibilidades de determinação de custos e preços (em virtude da diminuição do número de processos e atividades);

d) permite maior concentração em atividades consideradas como estratégicas;

e) abre um novo leque de possibilidades de controle da gestão da produção, principalmente sobre a força de trabalho, reduzindo os 
potenciais de luta do trabalho assalariado em razão da menor concentração de trabalhadores.

Segundo Leocádio, Dávila e Donadel (2008), a difusão da prática da terceirização por toda a cadeia de valor redefine a terceirização como uma transferência de atividades para fornecedores com uma base de conhecimentos especializados permitindo à empresa focar-se em sua atividade principal e receber de terceiros os bens e/ou serviços não diretamente ligados ao seu core business.

Ao utilizar trabalhadores terceirizados, as empresas adquirem maior flexibilidade gerencial. Os gestores podem examinar o desempenho dos terceirizados visando identificar aqueles que se sobressaem nas suas atividades para contratá-los diretamente no futuro. Como a demissão de trabalhadores é um ato custoso, ao invés de ter que demitir funcionários próprios, monitorar o desempenho dos terceirizados e contratar os que possuem alta performance é uma boa opção que as empresas têm para reduzir a necessidade de demitir funcionários no futuro (SEGAL; SULLIVAN, 1997).

São várias as forças que impulsionam o crescimento da terceirização. Uma delas é a maior ou menor regulação das relações de trabalho, expressa em legislações mais ou menos restritivas. Um exemplo interessante é que na década de 1990, na Europa, a rigidez do mercado de trabalho daqueles países acabou por influenciar também a terceirização. Na França, várias restrições legais são impostas às empresas em relação à efetuação de demissões. Por isso, a utilização de mão de obra terceirizada passou a ser utilizada na França para contornar as barreiras legais à demissão. Por outro lado, na Espanha e Portugal também existem essas restrições legais em relação à demissão. No entanto, são impostos às empresas limites para o uso de serviços terceirizados. Assim, o número de empregados diretamente contratados pelas empresas cresceu muito (SEGAL; SULLIVAN, 1997).

Ao optar pela terceirização as empresas também se deparam com problemas. Dentre eles destacam-se: a dificuldade de encontrar no mercado empresas qualificadas o suficiente para assumirem as atividades terceirizadas, os erros de interpretação das encomendas por parte das terceiras, produtos/ serviços que não atendem às especificações, desrespeito aos prazos e dificuldade em definir o grau de apoio a ser dispensado às contratadas. Há de se observar ainda os custos de transação oriundos da gestão de contratos $e$ as novas interfaces a serem geridas (GIOSA, 1993). 
Em geral, a terceirização envolve demissões nas empresas contratantes, o que tem acarretado inúmeras ações de natureza trabalhista. Os estudos nesse aspecto são inúmeros e atestam ainda uma considerável diferença de status (salariais, de condições de trabalho, condições de segurança, entre outros) entre efetivos e terceirizados. Os dados apontam que muitos trabalhadores foram expulsos do mercado formal das empresas, sendo absorvidos em outros empregos em condições precárias de trabalho (ANTUNES, 1999; POCHMAN, 2001; CARVALHO NETO, 2001).

Do ponto de vista do empregado, há certo consenso na literatura de que a terceirização tende a levar:

a) a uma precarização nas relações de trabalho;

b) a condições de empregos múltiplos e, via de regra, adversas;

c) ao recebimento de salários inferiores e abaixo do mercado;

d) a trabalhos sem formalização contratual e sem benefícios;

e) à atuação em condições de pressão acima da média; e

f) ao aumento da produtividade, e outros.

O terceirizado, embora exercendo as mesmas atividades, não absorve as conquistas trabalhistas e salariais do trabalhador efetivo, e via de regra, além dos reflexos imediatos no nível de emprego no longo prazo, tem-se como consequências a deterioração das condições de trabalho e a queda do nível de renda e da qualidade de vida dos trabalhadores (ANTUNES, 1995; BRESCIANI, 1997; COSTA, 1994; DEDECCA, 1996; SARSUR et al. 2002).

Em relação à empregabilidade dos trabalhadores, pesquisas mostram que essa é ainda em grande medida entendida como sendo a garantia da estabilidade no emprego em uma mesma empresa. No entanto, sabe-se que, atualmente, garantir um "emprego vitalício" é muito difícil. Dessa maneira, um dos meios para se reforçar a empregabilidade seria através da qualificação do empregado via treinamentos (FORRIER; SELS, 2003).

Falar em garantia de empregabilidade em uma mesma empresa para os trabalhadores terceirizados é uma questão complicada, devido à própria característica do trabalho temporário. Assim, a qualificação é importante para melhorar a empregabilidade deles. Um estudo de caso realizado na Bélgica indica que os empregados terceirizados possuem menos oportunidades de treinamento do que os diretamente contratados, por possuírem maior 
responsabilidade quanto à promoção de sua empregabilidade, já que são raras as empresas terceiras que propiciam boas oportunidades de treinamento, esses fatores contribuem para o fortalecimento da segmentação no mercado de trabalho (FORRIER; SELS, 2003).

Outro problema que diz respeito aos trabalhadores terceirizados, é que eles tendem a ser alvos de tratamento preconceituoso, na medida em que se forma uma concepção estereotipada deles. Tal estereótipo tem as seguintes características: possuem baixo conhecimento, pouca qualificação, pouca ética no trabalho e que são inferiores em relação aos trabalhadores das contratantes. Tal estigma certamente gera consequências negativas. Isso porque pode comprometer a autoestima, o bem-estar, a satisfação no trabalho, a performance e o comprometimento. Portanto, as empresas devem atentar para os fatores organizacionais e estruturais que levam à estigmatização dos trabalhadores terceirizados, pois isso leva a uma série de conseqüências negativas que podem ser um contrapeso considerável aos benefícios que as empresas aspiram atingir com a terceirização (BOYCE et al., 2007).

No Brasil, a terceirização tem sido tratada mais com o intuito de reduzir custos. Poucas empresas absorvem o sentido da parceria via contratos de fornecimento com garantia de qualidade, melhoria de produtos/serviços, transferência de conhecimentos, implicando efetiva relação de colaboração (COSTA, 1994). No caso brasileiro, a redução de custos é priorizada, quase que exclusivamente, em detrimento da qualidade, pois o que se visa é o incremento da competitividade via redução de custos (DRUCK, 1999). Assim, as grandes empresas buscam superar as crises transferindo parte do ônus para as empresas terceirizadas.

A terceirização cresce cada vez mais nas empresas brasileiras. A pesquisa de Sarsur et al. (2002), realizada em 349 grandes empresas brasileiras, indica que a natureza das atividades exercidas por terceiros está em toda a cadeia de valor. Fernandes e Carvalho Neto (2005) também constataram, pesquisando 179 grandes empresas, que os executivos pretendem continuar terceirizando e até mesmo aumentar o nível de terceirização.

Como a terceirização vem sendo amplamente utilizada no Brasil, os gestores vêm deparando-se com enormes desafios para lidar com tantos vínculos contratuais diferentes. Novas formas de relações de trabalho, como as oriundas da terceirização, implicam diferentes processos de gestão de pessoas, apontando novos desafios para os gestores. 
A pesquisa de Fernandes e Carvalho Neto (2005) foi realizada em 179 empresas brasileiras de grande porte, nas quais foram entrevistados 513 gestores sobre os desafios da gestão de múltiplos vínculos e as práticas de gestão de terceirizados para enfrentar esses desafios. Tal trabalho aponta que praticamente todas as situações enfrentadas pelos gestores são tidas como desafiadoras à gestão de terceirizados. Dos 38 desafios levantados por esses autores, 14 se destacaram como os maiores enfrentados pelas empresas na gestão de terceirizados. Desses desafios, em todos os cortes de análise realizados, concluiu-se que quatro se apresentaram como os principais desafios encontrados frente à gestão de terceirizados: contar com uma equipe qualificada de terceirizados; garantir a melhoria da qualidade de serviços; garantir a padronização dos serviços contratados e obter comprometimento dos terceirizados.

Os estudos de Costa (1994) e Faria (1994) já anunciavam alguns desses resultados, destacando que dentre os riscos comuns da contratação de terceiros estão a não conformidade do produto ou serviço em termos de qualidade, a falta de comprometimento e o não cumprimento de cláusulas contratuais por parte das empresas terceirizadas.

A pesquisa de Fernandes e Carvalho Neto (2005) atesta que, para enfrentar o desafio de contar com uma equipe qualificada de terceiros, $32,36 \%$ das empresas estudadas vêm investindo no processo formal da contratação, definindo os critérios, políticas e regras que orientarão a gestão do contrato de terceiros. A essa prática, complementam-se as seguintes: seleção dos terceirizados, estabelecimento dos objetivos e metas e acompanhamento e avaliação do desempenho. A segunda prática mais citada para lidar com esse desafio é o investimento em treinamento e desenvolvimento, apontada por $31,38 \%$ dos gestores entrevistados. Algumas empresas afirmam estender seus treinamentos aos terceirizados, enquanto outras desenvolvem treinamentos específicos. Embora aparecendo com menor incidência, algumas práticas de gestão vêm oferecendo aos gestores alternativas para a qualificação de terceiros. Contudo, essas não parecem ser soluções eficazes, mas sim paliativas. Nesse sentido, destacam-se a contratação de ex-funcionários como terceirizados e a própria redução dos terceirizados.

Quanto ao desafio de garantir a melhoria dos serviços, o destaque é a avaliação de metas estabelecidas, supervisão e feedback. Tal prática foi lembrada por quase $40 \%$ dos gestores entrevistados. Práticas de treinamento e desenvolvimento são novamente destacadas por $20,27 \%$ dos gestores. 
O estabelecimento de processos estruturados de certificação para as empresas terceirizadas é a terceira prática mais utilizada, sendo mencionada por $15,59 \%$ dos gestores. A incidência de respostas relativas à participação dos terceirizados no planejamento de trabalho e na troca de experiências foi mencionada por $14,62 \%$ dos gestores.

O desafio de garantir a padronização dos serviços de terceirizados foi o mais destacado pelos gestores entrevistados. Como resposta a esse desafio, a grande maioria dos gestores $(43,27 \%$ ) destaca o estabelecimento de processos estruturados visando à padronização dos serviços contratados, ao mesmo tempo em que exigem comprovação de certificação, como a ISO. Novamente destaca-se na opinião de $21,64 \%$ dos gestores, o acompanhamento do desempenho mediante avaliação de metas estabelecidas, supervisão e feedback; bem como a participação dos terceirizados no planejamento do trabalho e na troca de experiências, conforme mencionado por $14,42 \%$ dos gestores. Destacam-se também as atividades de treinamento e desenvolvimento, mencionadas por $13,45 \%$ dos gestores (FERNANDES; CARVALHO NETO, 2005).

Desafiados em obter maior comprometimento de terceirizados, $22,42 \%$ dos gestores entrevistados destacam a interação com os funcionários da empresa como prática destinada para lidar com esse desafio. Em segundo lugar, destacam-se na opinião de $15,98 \%$ dos gestores, o estabelecimento de relacionamentos de confiança e o compartilhamento de aprendizagem. A terceira prática, evidenciada pelos $12,09 \%$ dos gestores, é a oferta de premiações financeiras e possibilidade de contratação. Esse aspecto é ainda reforçado por $5,46 \%$ dos gestores que mencionam a remuneração justa como uma prática adotada para obtenção do comprometimento, enquanto $24,56 \%$ dos gestores entrevistados afirmaram que não utilizam nenhuma prática para lidar com esse desafio ou não responderam à questão (FERNANDES; CARVALHO NETO, 2005).

Considerando que os gestores das empresas pesquisadas representam uma amostra relevante do universo empresarial brasileiro, pode-se inferir, a partir da pesquisa de Fernandes e Carvalho Neto (2005), que existe pouca inovação nas práticas de gestão de terceirizados nas empresas brasileiras de grande porte, mantendo-se ainda um modelo tradicional, mais adequado para um ambiente com pouca diferenciação de vínculos contratuais, o que é oposto ao atual. 


\section{Metodologia}

Partindo da pesquisa quantitativa realizada por Fernandes e Carvalho Neto (2005), considerou-se que, para aprofundar na análise das práticas que lidam com os desafios da gestão múltiplos vínculos contratuais, a abordagem qualitativa permitiria avançar na compreensão desses desafios e práticas (GODOY, 1995).

O método escolhido para realização da pesquisa foi o estudo de caso. Eisenhardt (1989) aponta que o estudo de caso pode ser utilizado em pesquisas descritivas e para propiciar novas perspectivas em um tópico já pesquisado, como é o caso deste estudo. O estudo de caso permitiu análise profunda e criteriosa sobre as práticas de gestão utilizadas para lidar com os desafios relacionados aos múltiplos vínculos contratuais, a partir de evidências já coletadas em pesquisa quantitativa anterior.

No estudo de caso, a amostra não é aleatória e sim intencional, ou seja, o caso deve ser selecionado por alguma razão (EISENHARDT, 1989). A empresa onde foi realizada a pesquisa é a Vale, na sua planta sediada em Itabira, Minas Gerais. A Vale é atualmente uma das maiores companhias de mineração diversificada do mundo e tem uma relação com mais de 16.000 empresas terceiras. A escolha da empresa se deu por ser uma empresa de grande porte e que possui um elevado grau de utilização da terceirização, que ampliou ainda mais após o processo de privatização da empresa em 1997. Além desses motivos, é importante salientar a importância da empresa para o desenvolvimento de Minas Gerais e do país.

Os dados foram coletados por meio de entrevistas semiestruturadas e análise documental, o que proporcionou o alcance da variedade definida por Godoy (1995) como característica do método escolhido. Yin (2004) defende também que um ponto forte do estudo de caso é a oportunidade de utilizar muitas fontes diferentes para a obtenção de evidências. A análise documental reuniu documentos internos da organização que possibilitaram conhecer, do ponto de vista institucional, as práticas gerenciais adotadas para lidar com os desafios da gestão de terceirizados. As entrevistas foram realizadas com 15 dos 54 gestores de contratos de serviços terceirizados pertencentes à área de Gestão de Contratos de Itabira. Foram escolhidos para serem entrevistados os gestores fiscais de contratos que possuíam maior tempo de experiência como gestores de contratos envolvendo trabalhadores terceirizados. Esses gestores são responsáveis pela condução do processo de execução dos serviços terceirizados e lidam diretamente com os múltiplos 
vínculos de trabalho, pois além de lidarem com os terceirizados, contam com empregados efetivos da Vale a eles subordinados.

Constatou-se que dos entrevistados, seis são supervisores, cinco são analistas, um é geólogo, um é nutricionista e dois são gerentes de área. Eles estão, em média, há 15 anos na Vale e atuam como gestores fiscais de contratos há no mínimo dois anos. A maioria deles (13 dos 15 entrevistados) possui curso superior completo. Com exceção de um entrevistado, todo o grupo possui um número maior de trabalhadores terceirizados do que de efetivos atuando em suas equipes.

Os dados foram estudados por meio da análise de conteúdo, de forma a estabelecer uma relação entre os documentos pesquisados e as respostas

das entrevistas. Essa análise pode ser entendida como um conjunto de técnicas de análise de comunicação, visando, por procedimentos sistemáticos e objetivos de descrição do conteúdo das mensagens, obter indicadores que permitam a inferência de conhecimentos relativos às mensagens (BARDIN, 1977). Valendo-se da análise de conteúdo, foram desvendados os significados presentes nas verbalizações dos sujeitos entrevistados e nos dados provenientes da análise documental.

\section{Análise dos Dados}

A seguir, abordaremos como se deu o processo de terceirização na Vale e depois, discutiremos as práticas identificadas a partir das entrevistas realizadas com os gestores de contratos da Vale, para lidar com os desafios impostos pela terceirização.

\subsection{A Terceirização na Vale}

A Vale considera que a terceirização é "a prática de contratar terceiros para a realização de atividades que não constituem o objeto principal da empresa" (CVRD, 2005c, p. 2). Esse conceito está alinhado aos demais apresentados na revisão teórica e contraria outros estudos que indicam que a terceirização tem incluído atividades-fim das organizações.

A empresa ainda considera que os serviços terceirizados não devem ser permanentes e devem atender às demandas das áreas operacionais no médio e curto prazo (CVRD, 2005c). 
Na mineradora, a terceirização é regulada por diversas normas internas, dentre as quais destacam-se a Decisão do Conselho de Administração de 1999 (DCA 0079/1999) e a Decisão da Diretoria Executiva (DDE 0387/ 2003). Entretanto, o contrato de prestação de serviços é considerado o principal meio de regulação dos serviços terceirizados (CVRD, 2005c).

Embora a DCA 0079/1999 e a DDE 0387/2003 deixem claro que a economia de custos é um dos objetivos da terceirização, o Manual de Terceirização da Vale indica que os custos são próximos àqueles gastos com mão de obra própria (CVRD, 2005c). A busca de vantagem econômica é citada por Druck (1999) e Alves (2000) como uma das causas que levam grande parte das empresas à terceirização. Os gestores entrevistados confirmam que a redução de custos é fator decisivo para que atividades sejam terceirizadas na Vale. Entretanto, o discurso institucional da empresa considera que a vantagem econômica não pode vir a partir de prejuízos aos trabalhadores (CVRD, 2005c).

A política de terceirização da empresa esclarece que as atividades terceirizadas pela empresa não devem ser prestadas simultaneamente e na mesma unidade por terceirizado e efetivo. A Vale também não pode interferir na administração interna da empresa prestadora de serviços, devendo, unicamente, cobrar a execução das tarefas contratadas através dos prepostos (CVRD,1999). Essa preocupação se justifica pelo fato de que a subordinação é caracterizada como um vínculo empregatício, o que descaracteriza a terceirização. Como afirmado anteriormente, não deve haver qualquer tipo de ingerência da contratante em relação aos empregados das contratadas (SILVEIRA; SARATT; MORAES, 2002). Assim, constata-se a preocupação da empresa com um aspecto legal, que pode levar a prejuízos financeiros.

No geral, o processo de terceirização da Vale inicia-se com a busca de empresas especializadas na atividade a terceirizar e que se enquadrem nos parâmetros estabelecidos pela contratante. Verificaram-se, tanto nos documentos quanto nos relatos dos gestores entrevistados a preocupação com a qualidade dos serviços contratados e com a redução de custos. A busca por qualidade, inclusive, é considerada pela empresa como uma forma de cortar custos na medida em que evita o retrabalho e a perda de matériaprima. Assim sendo, não se pode afirmar que a Vale abre mão da qualidade, como fazem boa parte das empresas brasileiras na visão de Druck (1999), mas é possível alegar que a qualidade é considerada uma ferramenta para a redução de custos. 
Os gestores fiscais de contratos entrevistados demonstram conhecer as políticas de terceirização da Vale ao mencionarem os documentos que regulamentam o processo de terceirização e as principais normas estabelecidas pela Vale para a contratação e gestão de serviços terceirizados. $\mathrm{O}$ acesso às informações é facilitado por um sistema integrado de gestão empresarial, através do qual os gestores de contratos acompanham toda a execução da contratação das empresas terceirizadas, verificam a reputação das possíveis contratadas, liberam a aprovação do contrato e o pagamento das contratadas e têm acesso às informações relacionadas às tributações e impostos.

\subsection{Práticas Gerenciais para Garantir a Qualificação dos Trabalhadores Terceirizados}

O manual de terceirização da Vale estabelece que cabe à contratada fornecer mão de obra compatível com a atividade a ser desenvolvida. Os documentos analisados não apontam as práticas adotadas para garantir a qualificação dos trabalhadores terceirizados, mas os entrevistados apontam algumas práticas gerenciais nesse sentido (CVRD, 2005c).

A gestão de contrato é, segundo eles, a principal forma de garantir a qualificação. À gestão cabe verificar se as especificações acerca da qualificação dos terceirizados que são estabelecidas nos contratos são atendidas pelas contratadas. Normalmente a área requisitante da Vale aponta um perfil da qualificação desejada dos terceirizados e especifica apenas o perfil dos ocupantes de alguns cargos considerados mais estratégicos para a prestação daquele tipo de serviço. Cabe às empresas terceiras participantes do processo de licitação comprovar que têm profissionais com o perfil exigido.

A segunda prática utilizada para garantir a qualificação citada pelos gestores fiscais de contratos é o treinamento. Apesar de ser de responsabilidade das contratadas o treinamento e o desenvolvimento dos trabalhadores terceirizados, os gestores revelaram que a própria Vale arca com diversos treinamentos oferecidos aos trabalhadores, sejam eles efetivos ou terceirizados.

A terceira prática mais mencionada pelos gestores da Vale é o planejamento e contratação de objetivos e metas relacionadas à qualificação dos empregados das contratadas, como a participação dos empregados das contratadas no Programa Nacional de Qualificação e a certificação deles por meio do Centro de Exames de Qualificação. 
Aliada a tal prática está a avaliação de desempenho, quarta prática identificada. Os entrevistados deixam claro que é feita a avaliação das contratadas e não dos trabalhadores terceirizados.

A seleção é a quinta prática adotada para buscar a qualificação, entretanto, os gestores fiscais de contratos deixam claro que a seleção que a Vale faz é das empresas e não dos trabalhadores terceirizados: "a Vale contrata serviços e não mão de obra" (Entrevistado 6). Portanto, a prática da Vale converge com a afirmação de Silveira, Saratt e Moraes (2002). Segundo estes autores, a terceirização envolve pessoas jurídicas e não pessoas físicas, ou seja, não há relação direta entre a contratante e os empregados das contratadas.

O processo de seleção e contratação das empresas é criterioso e observa as especificações enviadas pelas áreas requisitantes. Os gestores afirmam que, além de serem especializadas nos serviços para os quais serão contratadas, as terceirizadas devem possuir idoneidade moral e financeira, garantir o cumprimento dos itens contratuais e a qualidade do produto final.

O controle da remuneração dos trabalhadores terceirizados (valor total pago a eles pelas contratadas), foi considerado uma sexta prática em busca da qualificação por seis dos 15 gestores entrevistados. Segundo esses gestores, um pacote de remuneração atrativo é capaz de reter os funcionários mais qualificados na empresa.

Outra prática nesse sentido, a sétima levantada pelos gestores, foi a contratação de empresas que têm trabalhadores que são ex-empregados da Vale, uma forma de garantir a qualificação dos terceirizados.

Práticas apontadas nesta pesquisa como as mais utilizadas pelos gestores de contratos da Vale coincidiram com as apontadas na pesquisa de Fernandes e Carvalho Neto (2005), como, por exemplo, a oferta de treinamento. É importante salientar que no caso da Vale, o treinamento é oferecido, muitas vezes, tanto para os efetivos quanto para os terceirizados.

\subsection{Práticas Gerenciais para Buscar a Qualidade dos Serviços Prestados pelas Empresas Contratadas}

Quanto ao desafio de garantir a qualidade dos serviços prestados por empresas contratadas, foram mencionadas por todos os gestores entrevistados as seguintes práticas: terceirização de atividades ou setores não estratégicos, contratação de empresas especializadas, gestão de contratos e avaliação das metas estabelecidas e seleção rigorosa das contratadas. 
A terceirização de atividades não estratégicas é mencionada em todos os documentos da empresa analisados. O serviço contratado deve ser a atividade-fim da contratada, que deve ter conhecimento suficiente para executar as tarefas (CVRD, 1999; 2003; 2005a; 2005b; 2005c).

Os gestores fiscais de contratos da Vale consideram que essa prática só é possível com a contratação de empresas especializadas na prestação de serviços, outra prática adotada pela contratante. A contratação de empresas realmente especializadas é apontada por diversos autores (DE RUIJTER et al., 2005; DRUCK, 1999; SERRA, 2004) como um ponto crucial para a efetividade de um processo de terceirização.

Segundo os gestores, a gestão dos contratos e a avaliação dos termos contratuais e das metas estabelecidas são práticas adotadas conjuntamente. A qualidade é estipulada e os gestores devem acompanhar periodicamente os serviços prestados, verificando se os termos contratuais estão sendo cumpridos. Essas avaliações servem de subsídio para o Cadastro de Fornecedores da Vale, um banco de dados composto por empresas que, a princípio, podem ser contratadas pela Vale.

A seleção rigorosa das contratadas também é uma prática mencionada por todos os gestores de contratos para garantir a qualidade dos serviços terceirizados. A partir do momento em que são selecionadas as empresas especialistas nas atividades terceirizadas, há uma maior garantia da qualidade dos serviços, que serão fiscalizados visando o alcance das metas estipuladas.

Oito dos 15 entrevistados mencionaram como prática para buscar a qualidade a contratação de empresas criadas por ex-empregados da contratante. Após a privatização da empresa, a utilização da terceirização foi acompanhada por um grande número de demissões. Diversos empregados demitidos tinham larga experiência no exercício de suas atividades e criaram empresas que hoje prestam serviço para a Vale e conseguem, de forma geral, vencer boa parte dos processos de licitação, já que um dos itens observados é a especialização.

A oferta de treinamentos, a certificação e a premiação das contratadas foram práticas utilizadas para garantir a qualidade dos serviços terceirizados mencionadas por nove dos 15 gestores entrevistados. Eles consideram que muitas vezes a diferença entre a qualidade esperada da estipulada no contrato da qualidade dos serviços prestados pelas contratadas é produto da falta de qualificação dos empregados dessas empresas, sendo necessário, portanto, o investimento em treinamentos. 
Em relação à certificação das contratadas, a Vale criou o Cadastro de Fornecedores, que é alimentado pelos resultados das avaliações dos serviços prestados pelas terceirizadas. A partir desses resultados as empresas contratadas recebem uma espécie de certificação, que permite que a empresa participe de outras licitações. A Vale pode cobrar das terceirizadas alguma outra certificação. Entretanto, em alguns casos, quando a Vale exige a certificação, pode ser que não existam empresas prestadoras daquele serviço ou esse se restrinja a um único fornecedor. Nesses casos, a empresa opta por abrir mão da exigência da certificação. A premiação das empresas contratadas, citada por nove gestores entrevistados como uma prática positiva adotada pela Vale, é um ponto de discordância entre os gestores. Segundo os outros seis gestores entrevistados, a premiação faz com que o padrão de qualidade estabelecido não seja visto pelas terceirizadas como uma condição mínima para a Vale aceitar o serviço, mas sim como uma condição máxima esperada e, por isso, passível de ser premiado.

Outras duas práticas foram mencionadas pelos entrevistados: a oferta aos trabalhadores terceirizados dos mesmos treinamentos oferecidos aos efetivos e contratos longos firmados entre a Vale e as terceirizadas.

Ao comparar as práticas utilizadas pela Vale para garantir a qualidade com as encontradas na pesquisa de Fernandes e Carvalho Neto (2005), percebe-se que a avaliação de metas estabelecidas, a oferta de treinamento $e$ o estabelecimento de processos são práticas comuns às duas pesquisas. Entretanto, a participação dos terceirizados no planejamento e na troca de experiências não foi mencionada pelos gestores fiscais de contratos da Vale, que, ao invés dessa prática, destacaram outras: terceirização de atividades não estratégicas, contratação de empresas especializadas, gestão de contratos, seleção e premiação das contratadas, contratar empresas criadas por exempregados, oferta aos terceirizados do mesmo tipo de treinamento dado aos efetivos e contratos longos firmados com as terceirizadas.

\subsection{Práticas Gerenciais para Contar com a Padronização dos Serviços Contratados}

A Política de Terceirização da Vale define que todos os padrões desejados devem estar definidos no escopo dos contratos. Todos os aspectos $e$ as condições relacionados às atividades terceirizadas, às normas, aos procedimentos e às responsabilidades envolvidas na execução estão nos 
contratos (CVRD, 2005c). Segundo os gestores, a padronização dos serviços terceirizados é vital para a qualidade dos produtos e serviços da Vale.

A gestão de contratos também é considerada a prática mais utilizada para lidar com o desafio da padronização e foi citada por todos os 15 gestores entrevistados. Segundo eles, a gestão de contratos permite fiscalizar se os padrões estipulados pela empresa são seguidos pelas contratadas. Nos contratos são estabelecidos os padrões que dizem respeito especificamente àquele tipo de atividade terceirizada. Esses estão relacionados à qualidade dos serviços, qualificação e remuneração dos terceirizados, equipamentos e materiais a serem utilizados. A fiscalização permite verificar se os padrões estão sendo seguidos.

Os critérios de avaliação dos serviços terceirizados também são padronizados (CVRD, 2005b). Os seguintes fatores são utilizados na avaliação de qualquer empresa contratada e encontram-se estipulados nos contratos: qualidade dos serviços; pontualidade na execução; cumprimento de normas trabalhistas e fiscais; cumprimento de normas de segurança no trabalho $e$ cumprimento da legislação ambiental.

Verifica-se, portanto, a existência do que Serra (2004) chama de subordinação técnica, ou seja, os empregados das contratadas da Vale seguem normas e procedimentos especificados pela contratante.

A segunda prática mais mencionada pelos gestores e também explícita nos documentos analisados é a certificação das empresas terceirizadas. Entretanto, como relatado anteriormente, há casos em que a certificação não é exigida por haver uma única ou poucas empresas que prestam o serviço a ser contratado.

Outra prática utilizada para lidar com o desafio da padronização é a avaliação das metas estabelecidas. Além da avaliação realizada pelos gestores fiscais de contratos, há também avaliações realizadas pelos gestores das áreas nas quais os terceirizados atuam. As metas mais mencionadas pelos entrevistados são as relacionadas à qualidade dos serviços, à segurança no trabalho e ao meio ambiente. O resultado da avaliação das metas alcançadas é repassado ao preposto da contratada, que elabora um plano de ação com o objetivo de proporcionar o alcance de todas as metas estabelecidas no contrato. Verifica-se mais uma vez a preocupação da contratante em não ter qualquer relação direta com os empregados das terceirizadas. 
Outra prática gerencial apontada pelos gestores é a oferta de programas de treinamento e desenvolvimento para os terceirizados. São realizadas avaliações após os treinamentos para verificar se os padrões foram assimilados.

Dois gestores afirmaram que é preciso entender que a padronização não significa que empregados efetivos e terceirizados devem executar as mesmas tarefas de maneira similar. A Vale proíbe que as mesmas tarefas sejam executadas por terceiros e por efetivos.

Das quatro práticas destacadas pelos gestores, três foram identificadas também na pesquisa de Fernandes e Carvalho Neto (2005). A pesquisa desses autores não apontou a gestão de contratos como prática gerencial para lidar com a padronização, mas apontou uma prática que os gestores fiscais de contratos da Vale não adotam: a participação dos terceirizados no planejamento do trabalho e na troca de experiências.

\subsection{Práticas para Lidar com o Comprometimento dos Trabalhadores Terceirizados}

As entrevistas com os gestores fiscais de contratos da Vale permitem afirmar que os terceirizados são comprometidos com o trabalho. Uma das causas do comprometimento dos terceirizados apontada pelos gestores é a importância da Vale para a cidade de Itabira, onde foi realizada a pesquisa. Segundo eles, o fato de trabalhar para uma contratada da Vale significa ter sucesso profissional e status (Entrevistados 3, 4, 9 e 13).

Dentre as práticas relacionadas pelos gestores, destacam-se a interação dos terceirizados com os funcionários da Vale e a possibilidade de efetivação, citadas por treze dos quinze entrevistados. A interação ocorre intencionalmente, segundo os entrevistados, em treinamentos, em horários de lanche e de almoço e em eventos realizados ou patrocinados pela contratante. Os terceirizados e os efetivos utilizam o mesmo transporte, participam de torneios esportivos promovidos pela Vale e integram as Comissões de Segurança e as Comissões de Prevenção de Acidentes, tendo os mesmos direitos e deveres que os efetivos. A possibilidade de contratação dos terceirizados pela Vale demonstra algo que os gestores tentam negar: a diferença entre os efetivos e os terceirizados. Se os últimos tentam fazer parte do grupo dos efetivos é porque a esse grupo são concedidas determinadas vantagens.

O estabelecimento de relacionamento de confiança, prática gerencial para lidar com o desafio do comprometimento, foi mencionado por dez 
gestores entrevistados. Entretanto, nota-se que o relacionamento entre os efetivos e terceirizados é dificultado pela impossibilidade de relação direta entre os empregados da contratante e os terceirizados. Para evitar problemas legais que poderiam ser interpretados como vínculo empregatício pela justiça do trabalho, a empresa contratante limita o relacionamento, o que pode afetar o comprometimento dos terceirizados.

Para buscar um maior comprometimento dos terceirizados, a Vale oferta treinamento de ambientação, no qual os valores, crenças e normas da empresa são transmitidos.

As premiações foram citadas pelos entrevistados como forma de buscar o comprometimento:

Na minha área guardo alguns prêmios que recebo de fornecedores para distribuir entre os funcionários das contratadas que se destacam. (Entrevistado 5)

Essa questão divide os gestores, pois parte deles tem receio de que a concessão de prêmios caracterize vínculo empregatício entre a Vale e os terceirizados. Os documentos analisados afirmam que qualquer tipo de gratificação dos terceirizados é de responsabilidade unicamente das contratadas (CVRD 2005a, 2005c). Os gestores que adotam essa prática afirmam que, embora vários gestores não admitam, há campanhas relacionadas à segurança no trabalho que envolvem premiação de efetivos e terceirizados.

A garantia de uma remuneração justa aos terceirizados também é considerada uma prática que leva ao comprometimento deste grupo de trabalhadores. A Vale exige que as contratadas ofereçam alimentação, transporte e plano de saúde aos seus empregados, e isso é especificado no contrato. As contratadas devem ter salários compatíveis com o mercado e observar o piso salarial de cada categoria profissional. Os gestores conferem mensalmente a folha de pagamento dos terceirizados e as guias de recolhimento do INSS e do FGTS. Anualmente são conferidas as carteiras de trabalho e os documentos comprobatórios das férias. Essa prática da Vale pode reduzir a discrepância de benefícios entre os empregados da contratante e os terceirizados mencionada por Druck e Franco (2007) e demonstra que é possível a influência da contratante sobre a remuneração oferecida pela contratadas sem que haja complicações legais. 
O compartilhamento de aprendizagem, segundo os gestores fiscais de contratos, também é capaz de fortalecer o comprometimento, e ocorre com a participação dos terceirizados em reuniões, dando sugestões e participando de decisões de diversos níveis. Esse é o único indício de participação dos terceirizados em decisões da empresa encontrado nesta pesquisa.

As práticas reveladas pelos ficais de contrato da Vale estão próximas das apontadas na pesquisa de Fernandes e Carvalho Neto (2005). Nas duas pesquisas, a interação dos terceirizados com os empregados da contratante é a prática mais utilizada.

\section{Considerações Finais}

A adoção da terceirização como forma de garantir maior flexibilidade gerencial foi adotada pela Vale seguindo a tendência das grandes empresas brasileiras. O crescimento de múltiplos vínculos contratuais representa um desafio para os gestores, pois esses passaram a ter sob sua supervisão, ao mesmo tempo, empregados efetivos, autônomos e trabalhadores terceirizados. Apesar desse desafio já durar pelo menos 20 anos, pouco ainda se discute sobre essas práticas gerenciais, e é nesse sentido que se constitui a maior contribuição desse artigo.

A Vale possui gestores de contratos que são capacitados para fiscalizar a execução dos serviços contratados. O olhar desses gestores sobre as práticas de recursos humanos em relação aos principais desafios impostos pela terceirização constitui-se em contribuição ainda mais rara, praticamente inexistente na literatura.

Todos os gestores de contratos entrevistados mencionaram práticas de gestão utilizadas para lidar com cada um dos desafios apresentados. Dentre as práticas encontradas, destaca-se a gestão de contratos, mencionada por praticamente todos os gestores, que revelam utilizá-la visando a qualidade e a padronização dos serviços contratados, bem como a qualificação dos trabalhadores terceirizados.

A oferta de programas de treinamento e desenvolvimento também se destaca como prática de gestão da Vale, sendo citada para lidar com todos os desafios, exceto o grande desafio de obter maior comprometimento dos terceirizados com a Vale. $\mathrm{O}$ treinamento tem como temas principais segurança no trabalho e normas de proteção ambiental. Por ser uma mineradora, a Vale 
executa atividades com alto grau de risco e de degradação ambiental. A empresa é fiscalizada principalmente nesses dois aspectos, o que explica o investimento e o foco no treinamento realizado pela empresa.

A atenção dada pela Vale à remuneração dos terceirizados também merece destaque. Verificou-se que esta preocupação se dá por dois motivos. Primeiro, por questões legais. Se as empresas terceirizadas contratadas pela Vale deixarem de cumprir qualquer obrigação legal com seus empregados, incluindo as obrigações relacionadas à remuneração, a Vale é co-responsável e pode ser condenada pela justiça a arcar com estas despesas num eventual contencioso trabalhista. O segundo motivo está relacionado ao fato de a empresa considerar a influência e a relação que a remuneração dos terceirizados tem com o comprometimento dos trabalhadores subcontratados, a qualidade dos serviços e a competitividade da companhia. Os gestores demonstraram perceber a importância do comprometimento e a sua relação com a qualidade dos serviços prestados. $\mathrm{O}$ comprometimento dos terceirizados pode não estar restrito às boas condições de trabalho e a uma remuneração "de mercado" - pois uma remuneração de mercado não significa que se trata de um bom salário. O comprometimento pode estar relacionado a uma eventual possibilidade de que um dia o trabalhador terceirizado venha a ser contratado como empregado da Vale. Numa escala menor, pode estar também relacionado ao status proporcionado por atuarem na mineradora, mesmo sendo terceirizados.

Outra preocupação constante dos gestores e explícita nos documentos analisados diz respeito à não configuração de um vínculo empregatício entre os empregados das terceirizadas e a Vale. Isso porque tal vínculo empregatício pode acarretar obrigações legais extras e, conseqüentemente, gerar custos para a empresa. Como a Vale considera que a terceirização deve levar à redução de custos - embora o Manual de Terceirização da Vale indique que os custos são próximos àqueles gastos com mão de obra própria -, essa apreensão se justifica. Os gestores fiscais de contratos não se dirigem diretamente aos trabalhadores terceirizados e não há efetivos e terceirizados executando uma mesma atividade. A única subordinação encontrada é a subordinação técnica, que não implica a existência do vínculo empregatício.

Através da presente pesquisa, observa-se que, ao temer o estabelecimento de vínculo empregatício com os trabalhadores terceirizados, a empresa contratante é impedida de avançar no tratamento dos desafios da gestão de terceirizados. Um desses exemplos é o estabelecimento de 
relacionamento de confiança, que é uma prática gerencial utilizada pelos gestores de contratos para lidar com o desafio de comprometimento. No entanto, por não ser permitida a relação direta entre os empregados da contratante e das contratadas, tal relacionamento é limitado, e isso impede que avanços no desafio de comprometimento dos trabalhadores terceirizados sejam auferidos.

Os gestores também têm o receio de que a concessão de prêmios aos trabalhadores terceirizados seja caracterizada como vínculo empregatício, pois qualquer tipo de gratificação aos terceirizados está a cargo das empresas contratadas.

Esses são exemplos de como a legislação trabalhista acaba por dificultar uma melhor integração entre os trabalhadores com diferentes vínculos contratuais, contribuindo até mesmo para que os terceirizados continuem segregados, uma vez que o temor das empresas em relação ao vínculo empregatício é justificável. Esse é um grande dilema para todas as grandes empresas no atual cenário brasileiro, ainda que se reconheça os esforços dos legisladores para proteger os trabalhadores terceirizados.

Outro ponto importante, é que apesar dos vários esforços para que se melhore o trabalho terceirizado, ele ainda é visto e tratado como sendo inferior ao emprego direto. Portanto, à gestão de terceirizados, cabe canalizar esforços visando identificar quais são os aspectos estruturais da terceirização que edificam esse estigma, responsável por influenciar negativamente os trabalhadores terceirizados.

De forma geral, a Vale possui práticas de gestão avançadas se comparadas às apontadas por Fernandes e Carvalho Neto (2005). Foi encontrada grande parte das práticas apontadas pelas 179 grandes empresas brasileiras pesquisadas por estes autores. As práticas utilizadas pela Vale deixam clara a preocupação com a redução de custos, mas não indicam que a empresa abra mão da qualidade e das condições de trabalho dos terceirizados.

Nesse contexto de ampla utilização da terceirização, a pesquisa indica a necessidade de práticas de gestão mais efetivas para lidar com os desafios impostos por esse processo. Ainda há uma longa jornada pela frente até que haja práticas de gestão realmente aptas para lidar com estes quatro desafios pesquisados e outros já existentes ou ainda por vir. Para que se evolua nesse sentido, é muito importante o investimento e o envolvimento da alta administração das empresas para desenvolver práticas de gestão mais avançadas e adequadas a um cenário que exige cada vez maior flexibilidade. 
Espera-se que esta pesquisa impulsione a realização de outras, e que o meio acadêmico possa contribuir efetivamente para a evolução das práticas de gestão para lidar com os múltiplos vínculos contratuais quando estes realmente se fizerem necessários. Como esta pesquisa não abrangeu os terceirizados nem as contratadas, sugere-se a realização de outra pesquisa para diagnosticar as condições de trabalho e de remuneração dos terceirizados e compará-las às oferecidas pela Vale.

\section{Multiple Challenges of Flexible Workforce Management: the contract managers experience}

\section{Abstract}

This article presents the results of a survey that had the purpose to evaluate the human resources (HR) practices adopted by a Brazilian industrial corporation from the viewpoint of contracting out managers to deal with four flexible workforce management challenges: qualification; quality; commitment; standardization of outsourcing services. These HR practices are still little discussed by scholars. So, this is the main contribution of this article. It is also virtually nonexistent in the literature studies that encompass analysis about HR practices to deal with major challenges of outsourcing throughout the viewpoint of contracting out managers. We performed 15 semi-structured interviews with contracting out managers. It was also performed a documental analysis about the rules of outsourcing practices of the corporation. We found management practices to deal with each of the four challenges presented. The management of contracts and the provision of training programs were the most prominent of the related practices. The results show that Brazillian labor laws contribute to the segregation of temporary workers, because the companies avoid a more direct relationship fearing legal constraints. Although several efforts were put to improve the work conditions of the flexible workforce, these workers are still stigmatized, seen and treated as less important than direct employers; this causes negative impacts on commitment. The decision to use flexible workforce by companies is still mainly due to cost savings. Therefore, there is still a long way to improve HR practices related to temporary workers in order to avoid losses for all the social actors envolved.

Key-words: Human Resources Management. Flexible Workforce Management Challenges. Contracting Out Managers. 


\section{Referências}

ALVES, G.. O Novo (e Precário) Mundo do Trabalho: reestruturação produtiva e crise do sindicalismo. São Paulo: Boitempo Editorial: FAPESP, 2000.

ANTUNES, R. Adeus Ao Trabalho? Ensaio sobre as metamorfoses e a centralidade do mundo do trabalho. São Paulo: Cortez, 1995.

. Os Sentidos do Trabalho: ensaio sobre a afirmação e a negação do trabalho. São Paulo: Boitempo, 1999.

ARRIGHI, G. O Longo Século XX. Rio de Janeiro: Contraponto, São Paulo: UNESP, 1996.

BARDIN, Laurence. Análise de conteúdo. Lisboa: Edições 70, 1977.

BOYCE, Anthony S. et al. Temporary Worker, Permanent Loser? A Model of the Stigmatization of Temporary Workers. Journal of Management, v. 33, n. 5, p. 5-29, fev. 2007.

BORGES, Â.; DRUCK, M. Crise global, terceirização e a exclusão no mundo do trabalho. Caderno CRH, 19:22-45, 1993.

BRESCIANI, Luís Paulo. Flexibilidade e reestruturação: o trabalho na encruzilhada. São Paulo em Perspectiva, São Paulo, v. 11, n. 1, p. 88-97, jan-mar. 1997.

CARVALHO NETO, Antonio. O Estado Concorrencial e as Mudanças na Natureza do Trabalho no Setor Público. RAC - Revista de Administração Contemporânea, Curitiba, v. 1, n. 2, p. 25-32, mai/ago 1997.

CARVALHO NETO, Antonio. Relações de trabalho e negociação coletiva na virada do milênio: um estudo em quatro setores dinâmicos da economia. Belo Horizonte: Vozes, 2001.

CLEGG, S. R.; HARDY C.; NORD, W. R. (Org). Handbook de Estudos Organizacionais. São Paulo: Atlas, 1999.

CORIAT, B. Automação Programável: Novas Formas e Conceitos de Organização da Produção. In: SCHMITZ, H.; CARVALHO, R. Q. Automação Competitiva e Trabalho: a experiência internacional. São Paulo: Ucitec, 1988. 
COSTA, Márcia da S. C. Terceirização/Parceria e implicações no âmbito jurídico-sindical. Revista de Administração de Empresas, São Paulo, v. 34, n. 1, p. 6-11, jan.-fev. 1994.

CVRD. Decisão do Conselho de Administração de 1999. Itabira: CVRD, 1999.

CVRD. Decisão da Diretoria Executiva de 2003. Itabira: CVRD, 2003.

CVRD. Contratação na CVRD. Itabira: CVRD, 2005a.

CVRD. Prática de Gestão de Contratos. Itabira: CVRD, 2005b.

CVRD. Terceirização na CVRD. Itabira: CVRD, 2005c.

DE RUIJTER, E.; TREAS, J.K.; COHEN, P.N. Outsourcing the gender factory: living arrangements and service expenditures on female and male tasks. Social Forces, Chapel Hill, v. 84, n. 1, p. 305-322, Sep. 2005.

DEDECCA, C. S. Racionalização econômica e heterogeneidade nas relações e nos mercados. In: OLIVEIRA, C.A.B. et al (Org.). Crise e Trabalho no Brasil. São Paulo: Scritta, 1996.

DRUCK, Maria da Graça. Terceirização - (Des)Fordizando a Fábrica: um estudo do complexo petroquímico. São Paulo: Boitempo Editorial, 1999.

DRUCK, Maria da Graça; FRANCO, T. (Org.). A perda da razão social do trabalho. São Paulo: Boitempo, 2007.

EISENHARDT, K. M. Building theories from case study research. The Academy of Management Review, v. 14, n. 4, oct. 1989.

FARIA, A. de. Terceirização: um desafio para o movimento sindical. In: MARTINS, Heloísa de Souza; RAMALHO, José Ricardo (Orgs.).

Terceirização: diversidade e negociação no mundo do trabalho. São Paulo: Hucitec: CEDI/NETS, 1994.

FERNANDES, M. E. R.; CARVALHO NETO, A. M. As práticas gerenciais frente aos principais desafios apontados pelas maiores empresas brasileiras na gestão de terceirizados. In: ENANPAD, 29., 2005, Brasília. Anais... Brasília: ANPAD, 2005. 
FORRIER, A.; SELS, L. Temporary Employment and Employability: training opportunities and efforts of temporary and permanent employees in Belgium. Work, employment and society, vol.17, n.4, pág. 641-666, dez. 2003.

GIOSA, L. A. Terceirização: uma abordagem estratégica. São Paulo: Pioneira, 1993.

GODOY, A. S. Pesquisa qualitativa: tipos fundamentais. Revista de Administração de empresas. São Paulo, v. 35, n. 3, p. 20-29, mai/jun. 1995.

HECKSCHER, C.; CARRÉ, F. Strength in Networks: employment rights organizations and the problem of co-ordination. British Journal of Industrial Relations, v. 44, n. 4, p. 605-628, 2006.

KOCHAN, Thomas A. The American Worker: disposable or indispensable? Work and Occupations, v. 33, n. 4, p. 377-381, nov. 2006.

KOLKO, J. Restructuring the world economy. New York: Pantheon,1988.

LEOCÁDIO, L. C. S; DÁVILA, G. A; DONADEL, A. C. Evolução da terceirização estratégica diante da gestão por processos. In: XI SIMPOI, 2008, São Paulo. Anais... São Paulo: FGV-EAESP, 2008. 1 CD-ROM.

LOCKE, Richard. O futuro das relações de trabalho e de emprego. In: CASTRO, Antonio Barros de; et al. O futuro da indústria no Brasil e no mundo: os desafios do século XX. Rio de Janeiro: Campus, 1999, p. 205-218.

OLSEN, K. M.; KALLEBERG, A. L. Non-Standard work in two different employment regimes: Norway and United States. Work, employment and society, v. 18, n. 2, p. 321-348, jun. 2004.

POCHMAN, M. O emprego na globalização. A nova divisão internacional do trabalho e os caminhos que o Brasil escolheu. São Paulo: Boitempo, 2001.

PURCELL, K.; PURCELL, J. In-sourcing, outsourcing, and the growth of contingent labour as evidence of flexible employment strategies. European journal of work and organizational psychology, London, v. 7, n. 1, p. 3959, 1998. 
RYNGELBLUM, A. L. Relacionamento entre desiguais: o papel da terceirização na reestruturação das grandes empresas. In: ENANPAD. 23, 1999. Foz do Iguaçu. Anais... Foz do Iguaçu: ANPAD, 1999.

SABEL, C.; ZEITLIN, J. Historical alternatives to mass production: politics, markets and technology in nineteenth-century industrialization. Past and present, 108, p. 133-176, aug. 1985.

SARSUR, A. M. et al. Repensando as relações de trabalho: novos desafios frente aos múltiplos vínculos de trabalho. In: ENANPAD, 26, 2002. Salvador. Anais... Salvador: ENANPAD, 2002.

SEGAL, L. M.; SULLIVAN, D. G. The Growth of Temporary Services Work. Journal of Economic Perspectives, v. 11, n. 2, p. 117-136, 1997.

SERRA, S. M. B. Qualidade na Terceirização. In: OLIVEIRA, O. J. (Org). Questão da qualidade: tópicos avançados. São Paulo: Pioneira Thomson Learning, 2004.

SILVEIRA, A. D.; SARATT, N.; MORAES, R. P. Um passo além da terceirização: a transferência de atividades e tecnologia. Porto Alegre: Badejo Editorial, 2002.

UDERMAN, S. Transformações produtivas e novos padrões organizacionais da Indústria: uma tentativa de sistematização do debate. Organização \&

Socieade. Salvador: v. 14; n. 42; jul-set., 2007.

WILLIAMSON, O. E. The Mechanisms of Governance. New York: Oxford University Press, 1996.

YIN, R. K. Estudo de caso: planejamento e métodos. Porto Alegre: Bookman, 2004. 